\title{
ОТ И.В. СТАЛИНА К Н.С. ХРУЩЕВУ: ТЕНДЕНЦИИ РАЗВИТИЯ СОВЕТСКОЙ ВНЕШНЕЙ ТОРГОВЛИ ВО ВТОРОЙ ПОЛОВИНЕ 1950-Х ГОДОВ*
}

В статье проанализированы тенденции развития советской внешней торговли во второй половине 1950-х гг. Выявлены причины (технологически-организационные, политические и структурные) отставания СССР от западных экономик, проанализированы проекты рефрормирования советской внешней торговли.

Ключевые слова: внешняя торговля, СССР, Н.С. Хрущев.

* Публикация подготовлена при поддержке Российского научного фонда, грант № 17-18-01728 «Мировая система социализма и глобальная экономика в середине 1950-х - середине 1970-х годов: эволюция теории и практики экономического и технологического лидерства». 


\section{FROM STALIN TO KHRUSHCHEV: TRENDS OF SOVIET FOREIGN TRADE IN THE SECOND HALF OF THE 1950s}

The article analyzed the trends in the development of Soviet foreign trade in the second half of the 1950s. The reasons (technologicallyorganizational, political and structural) of the USSR lagging behind the Western economies are revealed, the projects of reforming the Soviet foreign trade are analyzed.

Keywords: foreign trade, USSR, N.S. Khrushchev.

Монополия внешней торговли, объявленная большевиками практически сразу после их прихода к власти, составляла основу советской экономической модели. Не случайно, что после отмены монополии вконце 1980-х гг. социалистическая система распалась, не выдержав экономического давления. Несмотря на такое исключительное значение, история советской внешней торговли изучена крайне фрагментарно. Основное внимание историки и экономисты уделяли или отдельным статьям экспорта и импорта товаров, или внешнеторговым связям СССР с отдельными странами. Усилия исследователей как правило были сконцентрированы на изучении ленинско-сталинском периоде, тогда хрущевско-брежневское время осталось практически вне историографического поля. Исключением в этом отношении стали монографии О.С. Сибони [1] и М.А. Липкина [2]. Вместе с тем, именно в первые годы после смерти И.В. Сталина советская внешняя торговля претерпела существенную трансформацию. Впервые советское руководство стало рассматривать ее как один из эффективных инструментов мирной конкуренции с капиталистической системой, а также в качестве демонстрации достижений социализма.

Цель данной статьи: осветить тенденции развития советской внешней торговли во второй половине 1950-х гг. Выбранное время не случайно, так как этот период перехода от сталинской экономической модели к постсталинской, «хрущевской», заложившей основания для конструирования новых элементов мировой экономической системы социализма. В качестве ключевых источников использованы материалы, отложившиеся в бывшем текущем архиве ЦК КПСС - ныне Российском государственном архиве новейшей истории (далее - РГАНИ).

К 1960 г. советская внешняя торговля совершила колоссальный рывок в своем развитии. Так, общий товарооборот с 1953 по 1960 г. вырос почти вдвое - с 20,1 млрд р. до 46,6 млрд р. в год. В 1955-1960 гг. СССР в буквальном смысле ворвался на новые рынки, в первую очередь стран третьего мира - в Азиатском регионе и Африке. При Н.С. Хрущеве про- 
изошла существенная модернизация СЭВ, когда Совет стал превращаться в один из экономических институтов, успешно конкурировавших с капиталистическими аналогами.

Несмотря на феноменальное развитие советской внешней торговли, следует признать, что СССР все еще значительно отставал от ведущих индустриальных держав. В записке заместителя председателя Совета Министров СССР А.Ф. Засядько (которой мы коснемся чуть ниже) приводилась следующая любопытная статистика. По объему промышленного производства СССР к 1960 г. занимал второе место в мире, но только шестое по объему внешней торговли и 34 по объему внешнеторгового оборота в расчете на душу населения. СССР вывозил около 4 \% производимой продукции, тогда как США - 10 \%, ФРГ - 28 \%, Англия - 38 \%. Каковы были причины того, что СССР, имея столь впечатляющее возможности для развития внешнеторговых оборотов, значительно отставал от своих капиталистических конкурентов? Можно выделить несколько причин технологически-организационные, политические и структурные.

К технологически-организационным следует отнести общую техническую отсталость СССР по сравнению с западными странами. Например, в 1954 г. советский экспорт металлопродукции был не выполнен почти на треть, так как в СССР не было нужного количества вагонов, способных перевозить железную руду. Неоднократно на заседаниях Президиума ЦК обсуждались вопросы о неудовлетворительной работе того или иного министерства «по отгрузке машин, оборудования, приборов и запасных частей на экспорт», так как многие промышленные министерства не успевали изготовить экспортную продукцию в запланированном объеме. Технологическая отсталость СССР была видна в статистике по торговому флоту. К 1959 г. общий тоннаж торгового фрлота СССР составлял 3 млн т дедвейта и занимал 12 место в мире (первые три места - США, Англия, Либерия). Однако более 50 \% общего тоннажа приходилось на суда возрастом свыше 25 лет. Для фрахтования использовали иностранные корабли. Впрочем, технологическая отсталость была свойственна и другим соцстранам. В связи с возросшим объемом советского экспорта, железные дороги Польши и Чехословакии снизили пропускную способность. В итоге к январю 1957 г. на границе Польши и Чехословакии скопилось около 17 тыс. вагонов с экспортными грузами [3, д. 141, л. 68].

К организационно-техническим причинам стоит отнести и откровенно бюрократические. Например, вплоть до 1955 г. руководство МВТ не имело права принимать заказы на изготовление промышленных товаров в СССР, если они не соответствовали советским стандартам. Министерство не могло принять многочисленные заказы на поставку колесных тракторов в Индию, Бирму, Пакистан, Иран, Египет, Ливан, Турцию, Уругвай, так как большинство фирм просили поставлять тракторы с электростартером, что не было предусмотрено советским стан- 
дартом качества. Большой ущерб престижу советской внешней торговли наносил непостоянный и неустойчивый характер продажи отдельных советских экспортных товаров, в особенности, когда с экспорта снимались товары, потому что они не были включены в новый годовой план. Мелкие, на первый взгляд, детали тоже влияли на объем товарооборота. Например, в СССР не было пригодной тары для экспорта химикатов. Целый ряд товаров относился к стратегическим и по этим соображениям не вывозился. Но списки стратегических товаров не пересматривались с 1920-1930-х гг. Поэтому вплоть до начала 1960-х гг. «невывозными» были лакокрасочные изделия.

Негативно отражались на внешнеторговом балансе и политические причины. В 1954 г. в связи с «делом Петрова» СССР прекратил импорт и экспорт товаров в Австралию, в том числе, дешевой шерсти. Это привело к тому, что вплоть до конца 1950-х гг. Советский Союз был вынужден покупать шерсть у фирм-перекупщиков на 25-30 \% дороже. В 1956 г. в ходе Суэцкого кризиса советское руководство заявило о прекращении поставок несрти и мазута в Израиль [3, д. 135, л. 11].

Но все-таки следует признать, что таких демонстративных политических шагов со стороны СССР в рассматриваемый период было не так много. Руководство МИД и МВТ пытались отделить политику от экономики. Так, члены Президиума ЦК в апреле 1954 г. рекомендовали Минвнешторгу поставить на Совещании европейских стран по торговле, проходившем в Женеве 20 апреля 1954 г., вопрос об ограничении торговли с отдельными капиталистическими странами, занимающими враждебную позицию по отношению к СССР. Речь шла о сокращении торговли с Грецией, Норвегией, Пакистаном и Турцией. Однако ни МИД, ни МВТ не поддержали этой инициативы. Руководители министерств считали, что необходимо вводить не ограничения, а проявить «сдержанность и не идти на расширение торговли по нашей инициативе» [3, д. 129, л. 15]. Позиция министерств выражалась в следующем - внешнеторговый оборот с этими странами незначителен, а сокращение торговли уменьшит возможности СССР как-то влиять на политическую обстановку в них.

Но главной причиной, негативно отражавшейся на советской внешней торговле, были ее структурные изъяны. Советская внешняя торговля не отражала промышленного развития СССР. Советский экспорт, как и имперской России, почти на 70 \% состоял из сырья и материалов, топлива и зерна. К 1960 г. СССР занял второе место по производству химических товаров (уступив только США) - удельный вес СССР в мировой выработке продукции химической промышленности составлял $13 \%$, но доля в мировом экспорте достигала только 2 \%. СССР не экспортировал такие новейшие товары, как пластмассы, синтетические смолы и другие соединения. Денатурализации экспорта фрактически не произошло, напротив, с конца 1950-х гг. начался новый виток экспорта сырьевых то- 
варов, в первую очередь - нефти. Не поменялась и структура импорта товаров. Несмотря на увеличение экспорта товаров легкой промышленности, продовольствия, ключевые позиции в импорте сохранились за промышленным оборудованием, новейшими машинами, судами.

Конечно, на развитие советской внешней торговли негативно влияли не только внутренние причины, но и внешние, такие как мировые кризисы перепроизводства в той или иной области. Так, в 1954 г. Минвнешторг отмечал, что в связи с кризисом в добыче маргонцевых и хромовых руд, а также платины, заявленные в плане объемы продаж этой продукции не могли быть реализованы. Это привело к образованию дефицита внешнеторгового оборота в 180 млн р.

Далеко не все товары СССР мог напрямую закупить в капиталистических странах. Москва неоднократно сталкивалась с тем, что западные фрирмы отказывались сотрудничать с ней. Чаще всего это было связно с запретом на поставку промышленного оборудования в СССР. Такого рода запретительные санкции действовали в США. Так, правительственными инструкциями американским гражданам (независимо от страны, в которой происходят сделки) было запрещено продавать советским гражданам прокатное оборудование. В этих условиях представителям МВТ приходилось действовать через дополнительных контрагентов. Так, для того, чтобы закупить прокатные станки «Сендзимир», принадлежащие американской компании «Armzen», входящей в холдинг $\mathrm{ARMiCo} \mathrm{-} \mathrm{крупнейшую} \mathrm{американскую} \mathrm{сталепрокатная} \mathrm{компанию,} \mathrm{со-}$ ветской стороне приходилось проводить переговоры через австрийскую фирму и закупать оборудование через Югославию и Швейцарию. Англия, ФРГ, Италия, в которых производились прокатные станки «Сендзимир», отказывались от сотрудничества с Москвой из-за наличия экспортных ограничений. Например, немецкая фрирма «DEMAG» заявила, что может поставлять станки только в те страны, в которые разрешают американцы. Итальянская фирма «Innocenti» вначале сама проявила инициативу в поставках станков в СССР, но в дальнейшем также поменяла свою позицию. Вопрос даже обсуждался в итальянском правительстве, но в итоге итальянцы запретили экспорт станков в СССР.

Аналогичная история произошла в 1957-1958 гг. при попытках приобрести трубы большого диаметра и выдерживающих высокое давление. В ходе переговоров с западными странами, выяснилось, что американские и канадские компании не могут продать такие трубы, так как они находились в запретительном списке товаров для продажи СССР. Европейские страны (в первую очередь французские, английские, итальянские фирмы) тоже отказались их продавать. Европейцы мотивировали это загруженностью или отсутствием листа с соответствующими техническими показателями. Например, английская фрирма «Cookson» заявила, что может поставить только 5 тыс. т труб. Однако в последующем англичане от- 
казались от подобной поставки, мотивируя это тем, что у советской стороны не было листа с описанием технических характеристик [3, д. 84, л. 73].

Боялись сотрудничать с СССР не только развитые индустриальные державы, но и страны третьего мира. В частности, СССР не удалось наладить поставки натурального каучука из стран Юго-Восточной Азии. Индонезийцы и малайцы продавали каучук через Сингапур, Лондон, Голландию. Заместитель министра иностранных дел СССС Н.П. Фирюбин во время встречи с министром торговли и промышленности Малайской Федерации предлагал организовать прямые поставки каучука в СССР. Последний не проявил к этой идеи какого-либо интереса, заявив, что существующая система торговли каучуком через Сингапур и Лондон, вполне их устраивает. Представители Камбоджи отказались вести переговоры с Москвой о продаже каучука, так как опасались, что американцы прекратят оказывать им экономическую помощь.

Безуспешными были попытки СССР наладить импорт чилийской меди. Руководители Чили всегда положительно реагировали на подобные переговоры, но фактически использовали их для давления на США, для получения более выгодных условий продажи меди. Так, в сентябре 1953 г. чилийцы через аргентинского посредника предложили поставить в СССР в течение полугода 100 тыс. т меди. Правительство выделило MBT валюту для закупки 50 тыс. т меди. Были согласованы все условия контракта, но контакт так и не был заключен, так как чилийский сенат принял решение, запрещающее экспорт меди в СССР.

Характерно, что в Президиуме ЦК практически не рассматривались предложения по модернизации советской внешней торговли. Исключением стали две записки - министра торговли УССР Г.Л. Сахновского и заместителя председателя Совета Министров СССР А.Ф. Засядько. Записка Г.Л. Сахновского - это взгляд регионов на решение вопроса. Главная идея украинского политика заключалась в предоставлении больших свобод местным властям в формировании экспортно-импортных операций. В частности, Г.Л. Сахновский предлагал предоставить право республикам получать кредиты у иностранных фирм для покупки товаров, сначала краткосрочные (коммерческие), а дальнейшем долгосрочные. По мнению Г.Л. Сахновского, заказы от местных организаций помогли бы обойти торговые санкции: «Запрещение вывоза в страны Восточной Европы, особенно в СССР таких товаров возможно было бы преодолено хотя бы частично, если бы [организатором] выступали не торгпредства Министерства внешней торговли СССР, а скажем какой-нибудь коммунальный трест отдельного города, которому требуется оборудование или медный провод для электростанций» [3, д. 35, л. 74].

В 1956 г. Президиум ЦК рассмотрел предложения Г.Л. Сахновского. Впервые с ленинских времен (времен установления монополии внешней торговли) на повестке дня высшего руководящего органа КПСС обсуж- 
далось предложение о фактически децентрализации внешней торговли. Поразительнее всего то, что члены Президиума в итоге поддержали это предложение. В постановлении от 3 августа 1956 г. «О более активном участии союзных республик во внешней торговле», республиканским советам министров рекомендовалось расширить список экспортных товаров, пользующиеся спросом на мировом рынке» [3, д. 35, л. 172]. Выручка от продажи товаров руководители республик могли самостоятельно без согласования с центром использовать на увеличение импортных закупок. Годом позже Президиум ЦК утвердил постановление, разрешающее местным организациям расходовать до 70 \% средств, полученных от экспорта при выполнении плановых показателей, по своему усмотрению [3, д. 448, л. 60].

В записке А.Ф. Засядько затрагивались перспективы развития советской внешней торговли в глобальной перспективе. А.Ф. Засядько так определял приоритеты СССР на внешнеторговой арене: «В создавшихся условиях требуется резкая активизация внешних экономических связей Советского Союза с тем, чтобы они в полной мере содействовали решению коренных задач, стоящих перед нашей страной в области подъема экономики, дальнейшего укрепления мировой социалистической системы, сближения экономически слаборазвитых стран со странами социалистического лагеря и борьбы за установление прочного и длительного мира». В документе отдельно представлены тактики СССР с соцстранами, с капиталистическими странами и слабо-развивающимися странами.

Наиболее утопичные предложения А.Ф. Засядько озвучил по поводу взаимодействия с соцстранами. Автор подчеркивал, что к концу 1950-х гг. мировая социалистическая система представляла собой совокупность национальных экономических комплексов, каждый из которых развивался по собственному народнохозяйственному плану. В перспективе необходимо было превращение разрозненных национальных экономик в единое хозяйственное целое, устранение межгосударственных экономических барьеров. На практике это означало, что хозяйственные связи внутри соцлагеря должны были складываться не из межгосударственных взаимоотношений, а из отношений между отдельными экономическими районами единого мирового социалистического хозяйства, а основные народнохозяйственные пропорции должны формироваться как единый общий план мировой социалистической системы. «Процесс создания планомерного организованного мирового социалистического хозяйства как единого целого сопровождается сближением уровней хозяйственного развития отдельных стран, постепенным стиранием различий между ними в размерах производства промышленной и сельскохозяйственной продукции, а также национального дохода в расчете на душу населения, уровнях производительности труда и материального благосостояния народа». А.Ф. Засядько предлагал усилить помощь 
экономически слабым соцстранам (в том числе безвозмездную), таким как Румыния, Албания, КНДР, Монголия со стороны СССР, ГДР и Чехословакии. Автор записки призывал разработать документ о принципах и главных направлениях в разделении труда в соцлагере.

Более рациональные соображения были высказаны по поводу действий на рынках стран третьего мира и индустриальных стран. Так, Засядько предлагал усилить экономическую помощь слабым странам, выделяя ежегодно 1-2 \% национального дохода СССР на эти цели. По его расчетам к 1980 г. объем такой помощи должен был составить до 160 млрд р. На рынках капиталистических стран А.Ф. Засядько предлагал играть на противоречиях, в частности, на амбициях западноевропейских стран (в первую очередь Франции и ФРГ) по отношению к США.

Интересно так же, что хроническую проблему валютного десрицита А.Ф. Засядько предлагал решать за счет увеличения объемов сырьевого экспорта: «Природные ресурсы Советского Союза и его мощный производственный аппарат крайне слабо используются для расширения экспортной базы, что в конечном счете порождает хронические валютные затруднения и не дает возможности закупать на внешних рынках необходимые для народного хозяйства СССР сырье, оборудование и другие товары».

Записку А.Ф. Засядько, скорее всего, планировалось рассмотреть на пленуме или на Президиуме ЦК. Об этом свидетельствует тот факт, что хотя автором ее является А.Ф. Засядько (на это неоспоримо указывают сопроводительные документы), но в конце ее стоит машинописная подпись Н.С. Хрущева. Возможно, предложения А.Ф. Засядько, озвученные Н.С. Хрущевым, должны были превратиться в своеобразную программу действий СССР на внешнеторговой арене. Однако в итоге эта записка так и не стала предметом обсуждения высших партийных инстанций, a ее истинный автор информировал заведующего Общим отделом В.Н. Малина о снятии вопроса с рассмотрения. Можно лишь догадываться о том, почему же предложениям, озвученным в документе, не был дан ход. Вполне возможно, что причиной этого стал начавшийся резкий пересмотр международных отношений, после провала Парижского саммита великих держав [2, с. 318-323].

Середина 1950-х гг. стала не только временем смены советской политической системы (переход от сталинской системы управления к коллективной), изменился подход советского руководства во взаимодействии с внешним миром. Н.С. Хрущев фрактически отказался от потенциального военного противостояния с капитализмом и объявил о мирном сосуществовании двух систем. Это повлекло за собой усиления конкуренции с Западом в первую очередь в экономической сфере. Внешняя торговля стала использоваться советскими руководителями в качестве инструмента для демонстрации потенциала возможностей советской системы 
перед капитализмом и раскрытия альтернативных путей развития мировой экономики. Увеличение внешнеторговых оборотов СССР было обусловлено не только внешними, но внутренними причинами. Необходимость модернизации промышленности, а главное увеличение объемов гражданской экономики (в первую связанной с производством товаров массового потребления), заставляли СССР более активно действовать на внешнем рынке. Несмотря на бюрократическую неповоротливость советского внешнеторгового аппарата, жесткую конкуренцию со стороны западных производителей, вторая половина 1950-х гг. стала «золотым» временем деятельности СССР на внешнеторговой сфере. СССР не только трансформирует систему внешнеторговых связей с социалистическими странами (открывается второе дыхание в деятельности СЭВ), но и становиться активным игроком на рынках капиталистических стран и, в первую очередь, стран третьего мира. Вместе с тем именно в этот период ярко высветились негативные явления, такие как увеличение экспорта нефте-ресурсов и росте импорта дорогостоящего промышленного оборудования. Вторая половина 1950-х гг. стала временем своеобразной исторической развилки, когда советскому руководству выбрать путь дальнейшего экономического развития страны, используя в том числе ресурсы советской внешней торговли.

\section{Список использованной литературы и источников}

1. Sanches-Sibony O. Red Globalization. The political economy of the Soviet Cold War from Stalin to Khrustchev / O. Sanches-Sibony. - Cambridge, 2014.

2. Липкин М. А. Советский Союз и интеграционные процессы в Европе: середина 1940-х - конец 1960-х гг. / М. А. Липкин. - М. : Русский фонд содействия образованию и науке, 2016. - 560 с.

3. Российский государственный архив новейшей истории. - Ф. 3 (Политбюро ЦК КПСС). - Оп. 12.

\section{Информация об авторах}

Джалилов Теймур Агабаевич - кандидат исторических наук, научный сотрудник, Институт всеобщей истории РАН, 119334, г. Москва, Ленинский пр., 32а; начальник Отдела подготовки к публикации архивных документов, Российский государственный архив новейшей истории; 115035, г. Москва, Софийская набережная, 34, стр. 1; e-mail: slavika1@yandex.ru

Пивоваров Никита Юрьевич - кандидат исторических наук, старший научный сотрудник, Институт всеобщей истории РАН, 119334, г. Москва, Ленинский пр., 32а; главный специалист Отдела подготовки к публикации архивных документов, Российский государственный архив новейшей истории; 115035, г. Москва, Софийская набережная, 34, стр. 1; e-mail: pivovarov.hist@gmail.com

\section{Authors}

Teymur A. Jalilov - PhD in History, Researcher, Institute of Universal History of the Russian Academy of Sciences, 32a Leninsky prospect, 119334, Moscow, Russia; 
Head of the Department of Preparation for Publication of Archival Documents, Russian State Archive of Recent History, 34 bld. 1, Sofiyskaya Embankment, 115035, Moscow, Russia; e-mail: slavika1@yandex.ru

Nikita Yu. Pivovarov - PhD in History, Senior Researcher at the Institute of Universal History of the Russian Academy of Sciences, 32a Leninsky prospect, 119334, Moscow, Russia; Chief Specialist of the Department of Preparation for Publication of Archival Documents, Russian State Archive of Recent History, 34 bld. 1, Sofiyskaya Embankment, 115035, Moscow, Russia; e-mail: pivovarov.hist@gmail.com 